been preserved, and how nearly it resembles the similar parts of modern Foraminifera. He thinks, however, that these round and regularly branching forms are rather exceptional, which is a mistake; though it is true that the sections of the larger canals are often somewhat flattened, and that they become. flat where they branch. They are also sometimes altered by the vicinity of veinlets or fractures, or by minute mineral segregations in the surrounding calcite, accidents to which all similar structures in fossils are liable. Another objection, not original with him, is derived from their unequal dimensions. It is true that they are very unequal in size, but there is some definiteness about this. They are larger in the thicker and earlier formed layers, smaller or even wanting in the thinner and more superficial. In some slices the thicker trunks only are preserved, the slender branches having been filled with dolomite or ealcite. It is difficult, also, to oblain, in any slice or any surface, the whole of a group of canals, 1 Further, as I have shown, the thick canals sometimes give off groups of very minute tubes from their sides, so that the coarser and finer canals appear intermixed. These appearances are by no means at variance with what we know in other organic structures. Another objection is taken to the direction of the canals, as not being transverse to the lamina but oblique. This, however, may be dismissed, since Moebius has of course to admit that it is not unusual in modern Foraminifera. It may be added that some of the appearances which puzzled Moebius, and which are represented in his figures, evidently arise from fractures displacing parts of groups of canals, and from the apparently sudden truncation of these at points where the serpentine filling gives place to calcite. It would also have been well if he had studied the canal systems of those Stronca. topora which have a secondaiy or supplemental skeleton, as Canostroma and Caunopora.

4. A fatal defect in the mode of treatment pursued by Mocbius is that he regards each of the structures separately, and does not sufficiently consider their cumulative force when taken together. In this aspect, the ease of Eozöon may be presented thus: ( $I$ ) It occurs in certain layers of widely distributed limestones, evidently of aqueous origin, and on other grounds presumably organic. (2) Its general form, lamination, and chambers, resemble those of the silurian Stromatopora and its allies, and of such modern sessile foraminifera as Carpenteria and Polytrema. (3) It shows under the microscope a tubulated proper wall similar to that of the Nummulites, though of even finer texture. (4) It shows also in the thicker layers a secondary or supplemental skeleton with canals. (5) These forms appear more or less perfectly in specimens mineralised with very different substances. (6) The structures of Eozöon are of such generalised character as might be expected in a very early Protozoan. (7) It has been found in various parts of the world under very similar forms, and in beds approximately of the same geological horizon. (8) It may be added, though perhaps not as an argument, that the discovery of Eozöon affords a rational mode of explaining the immense development of limestones in the Laurentian age; and on the otber hand that the various attempts which have been made to other hand for the structures of Eozöon on other hypotheses than that of organic origin have not been satisfactory to chemists or maineralogists, as Dr. Hunt has very well shown.

Prof. Moebius, in summing up the evidence, lhints that Di: Carpenter and myself have leaned to a subjective treatment of Eozoon, representing its structure in a somewhat idealised manner. In answer to this it is necessary only to say that we have given photographs, nature-prints, and camera-tracings of specimens actually in our possession. We have not thought it desirable to figure the most imperfect or badly preserved specimens, though we have taken pains to explain the nature and mens, though defects. Of course, when attempts at restoration have been made, these must be taken as to some extent conjectural; but so far as these have been attempted they have consisted merely in the effort to eliminate the accidental conditions of fossilised bodies, and to present the organism in its original perfection. Such restorations are not to be taken as evidence, perfection. jillustrations to enable the facts to be more easily understood. It is to be observed, however, that in the study of such fossils as Eozöon, the observer must expect that only a small proportion of his specimens will show the structures with any approach to perfection, and that comparison of many speci. mens prepared in different ways may be necessary in order to

I have succeeded best in this by etching the surface of broken specimens understand any particular feature. A single figure or a short description may thus represent the results of days spent in the field in collecting, of careful examination and selection of the specimens, of the cutting of many slices in different directions, and of much study of these with different powers and modes of illumination. My own collection contains hundreds of preparations of "Eozöon, each of which represents perhaps hours of labour and study, and each of which throws some light more or less important on some feature of structure. The results of labour of this kind are unfortunately ve:y liable to be regarded as subjective rather than objective by those who arrive at con. clusions in easier ways.

Taken with the above cautions and explanations, the memoir of Prof. Moebius may be regarded as an interesting and useful illustration of the structures of Eozöon, though from a point of view somewhat too limited to be wholly satisfactory.

\section{THE COLOURS OF DOUBLE STARS}

IN a recent number of the Bulletin de l'A cadémie roy'ale de Beloique, M. Niesten, of the Brussels Observatory, has pub. lished some interesting details relating to the colours of double stars, to which subject he has given special attention for a considerable time past. When comparing the periodicity of solar. spots with the longitudes of planets in the ecliptic, Messrs. De la Rue, Balfour Stewart, and Loewy had found that a distinct connection exists between solar activity and the relative positions of the different members of our planetary system. A long time ago the attention of astronomers had already been drawn to the fact that Wolf's sun-spot period of eleven years coincides witl. the period of Jupiter's revolution rund the sun. Later on Prof. Balfour Stewart pointed ont that the coincidence of tie peribeliz of Jupiter and Saturn, which occurs about every fifty-nine years, corresponds to another one of Wolf's spot.periods.

If, therefore, the relative positions of the planets with regari to the sun bave some infuence upon the activity of that luminary, the question is justifiable whether on the other hand the influence of the sun upon the planets might not be apparent through some slight changes in their colour. There is no doubt that the colours of the planets actually do change; their brightness increases and decreases according to their position near the perihelion or aphelion. In the case of Jupiter changes of colour have been repeatedly observed, and they seem to coincide with the sun-spot periods. At the last opposition of Mars, when the planet was near its perihelion, it seemed to be less ruddy than usual: Uranus, which was generally described as shining with pale bluish light, is now, when it is approaching its perihelion, remarkable by its bright white lustre.

These relations between the sun and the planets induced $M$. Niesten to search for similar relations among the double stars and specially to try to answer the question whether the changes of colour which have taken place in several double-star systems are in any way connected with the relative position of the com pouents of a double star. For this purpose he collected the observations of astronomers who have given special attention to the colours of stars, and catalogued the colours of the stars visible in our horizon. It was found that many double-stars have not changed in colour since they were first observed, while others in a period of more or less considerable duration have shown 2 series of changes of colour, which seem to follow a. defmite law. The changes of colour were particularly remarkable in those double stars which possess great velocity of revolution. M. Niesten gives a table in which the different colours of twenty double stars of known period and periastrium, i.e., the colours of the principal star and of the companion, as observed. at different periods, are compiled. From M. Niesten's discussion of the facts revealed by this table, ne will give that relating to the first two double-star systems by way of example.

In $70 p$ Ophiuchi, the period of revolution of which is $94^{\circ} 3$ ? years, and for which the periastrium occurred in 1807 , the colout of the principal star at Herschel's time (an epcch closely preceding the periastrium) was white; the star then changed in colour; passing from white, through yellow and pale topaz.coloured to golden yellow, reaching this tint about 1854 . From this period it showed a tendency to return to white, passing through yellow: and pale yellow. In $1877 \mathrm{Mr}$. Pritchard designated it as pale yellow, and afterwards as white. The companion during its revolution showed similar fluctuations of colour to those of the principal star. In the vicinity of the periastrium Herschel put it down as reddish (we must remember here that Herschel's 
speculum gave a slight redish tint to all objects); now the coninpanion is bluish white, and between these two epochs it showed pmore saturated colours.

The short period of $g$ Herculis ( $34^{\prime} 32$ years) allows us to consider the changes of cclours during two revolutions. Herschel measured this system about the epoch when the companion was very near to the primary; the latter was white, the former ashcoloured. At the periastrium of $1860 \mathrm{Mr}$. Knott saw thein pale yellow and greenish respectively; at other epochs the colours of the two components are all the more marked the further they are away from the periastrium, the companion always showing warmer tints than the principal star. About the epoch of the apparent periastrium M. Dembowsky designated them as yellow and olive coloured. Similar phenomena are shown by the other double stars given in the table, all of which are systems with closed, i.e., elliptical orbits. In the double star $6 \mathrm{r}$ Cygni, where no closed orbit has been observed, but where the small companion moves in a stiaight line relatively to the larger one, the same yellow tint has been observed from 1828 to 1873 .

In the cases of optical double-star systems, i.e., those which only accidentally happen to be in the same line of sight, and which show a rectilinear motion, the principal star is generally yellow and the companion blue. In Mr. Brothers' catalogue, which comprises 105 double-star systems, with closed orbits, there are only thirty-two where the companion is blue, while all the others show the same colour as the principal star. And even toese thirty-two systems may possibly be optical ones, in which the companion is almost exclusively blue. The absence of blue in the companions of double stars of short period is most remarkable.

The blue colour of the companions in the optical systems is not an effect of contrast to the yellow colour of the primaries, for the former are blue even if the latter are shut out of the feld of vision. It seems possible that, similar to the effect in our atmosphere, where distant objects assume a bluish tint, celestial bodies which send us their rays of light from the most distant regions, may appear blue on account of the thickness of tine medium through which the light passes.

M. Niesten has compiled a table of double stars with blue companions, and has arranged them according to their position in declination and right ascension. From this it appears that these double stars are principally situated in a zone extending from decl. $10^{\circ} \mathrm{S}$. to $40^{\circ} \mathrm{N}$., and further "that there are two maxima of occurrence, one in R.A., $4 \mathrm{~h} .-6 \mathrm{~h}$, and the other in R.A. I $8 \mathrm{~h},-20 \mathrm{~h}$.; the first maximum is near the equator, the other between Decl. $30^{\circ}$ and $40^{\circ} \mathrm{N}$.; the former is therefore in the constellation of Orion, the latter in Cygnus and Lyra. According to Sestini, the single blue stars occur in the same parts of the heavens.

The conclusions we may draw from M. Niesten's researches are as follows:-

I. In systems with well-established orbits, and particularly in those of short period, the two components generally bave the same yellow or white colours.

$\therefore 2$ In systems of which we possess sufficiently numerous records of the colours of the components to enable us to perceive a relation between the tints and the relative positions of primary and companion, the former is white or pale yellow when the latter is in its periastrium, while in other positions the primary is yellow, golden yellow, or orange.

3. In these systems the companion follows the colour-fluctua. tions of the principal star, and frequently surpasses the latter in intensity of tint the further it moves away from the periastritm, at which point in most cases its light is white, like that of the primary.

4. An equality of tints of primary and companion is found in systems with rectilinear motion, as well as in those with closed orbits and long periods.

5. In optical groups the companion is generally blue.

These remarks are, of course, founded upon observations made by different observers, and the records of colour may thus suffer from personal influences; but in many cases one and the same observer recorded the colours of the components of a system as yellow during a series of years, and then he saw them grow paler and tum white. In other instances all astronomers agree that a certain companion is blue.

When more careful attention has been given to the question of colours, both in measuring double stars as well as in investiga tions of the physical condition of planets, then it will be possible, perhaps, to draw a great many more conclusions, and suck to which greater probability attaches, than was in the power of $M$. Niesten, with the comparatively small number of observations at his command.

At present it is supposed that the fluctuations of colour in stars are caissed by changes in the composition of their incandescent gaseotis envelopes; these changes must in turn be only effects of another cause producing them; M. Niesten does not think it inpossible that in the case of double stars this cause migtt lie in the relative position of the components.

\section{SCIENTIFIC SERIALS}

American Chemical Fournal, vol. i., Nos. 2 and 3 , present a good array of contributions from different American universities, making in all, witl reviews and reports, about 215 pages. Under inorganic chemistry is to be found a description of very slightly modified methods of nitrogen and phosphorus estimation adapted to agricultural products, by Johnson and Jenkins; and a series of analyses of gummite and other uranium minerals from North Carolina, by E. Genth, \&c. Among the contributions to organic chemistry is a long paper by Remsden and Iles on the oxidation of substitution products of aromatic hydrocarbons, continued from No. I. In the first portion the authors describe solid orthokresol from their oxytoluic acid, and they further conclude from their experiments that the presence of a sulphamine group acts protectively towards a methyl group in a substituted aromatic compound submitted to oxidation. A full abstract of this and another interesting paper by Remsden and Morse on oxiclation of bromparaethyltoluene, and researches on substituted benzyl compounds, by Jackson, cannot be given in our space. Thorpe on heptane has appeared elsewhere. The reanining comminications are of minor interest.

Bullein de la Acadénziz Royale des Sciences (de Beloique), No. 5. - The yellow substance obtained when tetrathionic acid is poured into a solution of mercurous nitrate in water has been proved by M. Spring to be a trithiobasic sulphate of mercury. This substance showed some unexpected chemical properties, which $M$. Sp:ing describes, and he has succeeded in forming some other new bodies similar to it, so as to complete the list of basic suluhates of mercury sufficiently for an attempt at classifi. cation of these substances. - The recent terrible catastrophe at the Agrappe coal-pit is the occasion of two communications by M. Cornet and M. Melsens, the former remarking especially on the inflizence of depth on the instantaneous irruption of fire damp. and the proportion of that gas met with. (The fire-damp of the Agrape pit, which ignited at the mouth of the pit, came from 6ro metres depth, where a new gallery was being made.) M. Renait's paper on the distinctive characters of dolomite and calcite in rocks of the carboniferous limestone of Belgium is elsewhere noticed.-There are also here two notes on Belgian minerals.

THE Rivista Scicntifico-Industriale, Nos, II-I3, contain the following papers of importance :-Researches on the electric conducting power of carbons, by Prof. Rinaldo Ferrini.-On some new applications of the potential energy of liquid surfaces, by G. Van der Mensbrugghe, discussed by Prof. C. Marangoni. -On a telephonic microphone, by Prof. G. Cantoni.-On the endosmose of liquids and on an apparatus for filling endosmometers, by Prof. C. Marangoni.-On the mutual dependence of simple bodies, by P. Provenzali.-On some prehistoric discoveries made at Ostiano, by $\mathrm{Dr}$. Ciro Chistoni.--On a new saccharometer or polarimeter, by M. Laurent.- On the kinzigite of Calabria, by Domenico Lovisato. - On the determining calses of the sexuality of Cannabis sativa, by Prof. P. A. Saccardo.On the constitution of fog and clouds, by Prof. Fernando Palagi. - On a new burner for monochromatic light.-On the phenomena which accompany the electrolysis of metallic compounds, by Prof. Giuseppe Basso.-Crystallographical, optical, and chemical researches on certain minerals, by Prof. Giuseppe Grattarola.-On a new method to determine the melting-point of organic substances, by Prof. Giorgio Roster.

THE Revne Internationale des Sciences (June and July).From these parts we note the following papers :-Analysis of Prof. Ernst Haeckel's treatise, "Monogenetic and Polygenetic Origin of the three Organic Kingdoms and of the Organs," by Jules Soury.-Description of the scientific balloon ascent of October $3 \mathrm{I}$, I878, and remarks on the exploration of great aërial heights, by Louis Tridon. - On the Diatomacea of the mouth of 